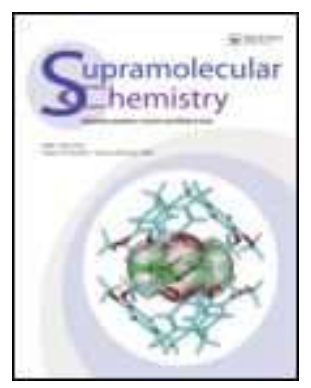

\title{
Stimulated by cyclodextrins high yield synthesis of azocrown analogues comprising pyrrole or imidazole residues
}

\begin{tabular}{|r|l|}
\hline Journal: & Supramolecular Chemistry \\
\hline Manuscript ID: & GSCH-2007-0120.R1 \\
\hline Manuscript Type: & Full Paper \\
\hline Author: & 16-Oct-2007 \\
\hline $\begin{array}{l}\text { Complete List of Authors: } \\
\text { Kabmitted by the }\end{array}$ & $\begin{array}{l}\text { Sechnology } \\
\text { Jamrógiewicz, Marzena; Gdansk University of Technology, Chemical } \\
\text { Technology } \\
\text { Biernat, Jan; Gdansk University of Technology, Dept. of Chemical } \\
\text { Technology }\end{array}$ \\
\hline $\begin{array}{l}\text { Keywords: } \\
\text { cyclodextrin(s), bis-diazonium salts, azoles, macrocyclic compounds }\end{array}$ \\
\hline $\begin{array}{l}\text { Note: The following files were submitted by the author for peer review, but cannot be converted } \\
\text { to PDF. You must view these files (e.g. movies) online. }\end{array}$ \\
\hline $\begin{array}{l}\text { scheme1.cdx } \\
\text { scheme2.cdx } \\
\text { scheme3.cdx } \\
\text { scheme4.cdx }\end{array}$ \\
\hline
\end{tabular}

\section{(5) ScholaroNE" \\ Manuscript Central}




\title{
Stimulated by cyclodextrins high yield synthesis of azocrown analogues comprising pyrrole or imidazole residues
}

\author{
KAMILA SADOWSKA, MARZENA JAMRÓGIEWICZ ${ }^{\diamond}$ and JAN F. BIERNAT
}

Department of Chemical Technology, Gdańsk University of Technology, Narutowicza 11/12 80-952 Gdańsk, Poland

Keywords: cyclodextrin, bis-diazonium salts, azoles, macrocyclic compounds

The influence of cyclodextrins on formation of azocrown ethers comprising pyrrole, imidazole and substituted imidazole has been studied. Pyrrole, imidazole, 2-methyl-, 4methyl- and 4-phenylimidazole were coupled with bis-diazonium salts derived from bis1,5-(2-aminophenoxy)-3-oxapentane or bis-1,8-(2-aminophenoxy)-3,6-dioxaoctane to form macrocyclic compounds with two azo units. The syntheses were performed under standard conditions in the presence of $\alpha-, \beta$-, or $\gamma$-cyclodextrin (CDs) and the yield of the reaction products was compared with the results of plain experiments, i.e. without CDs. The results are discussed in terms of co-conformation of azole molecules embedded in cyclodextrin cavity.

\footnotetext{
$\checkmark$ Present address: Medical University of Gdansk, Faculty of Pharmacy, Department of Physical Chemistry.

*Corresponding author. Tel. +48-58-347-10-56; fax: + 48-58-347-19-49; e-mail: biernat@ chem.pg.gda.pl
} 


\section{Introduction}

Cyclodextrins found wide application in contemporary chemistry due to their ability to form host-guest complexes [1]. Molecules encapsulated inside CDs are at least partially protected against reactions [2,3], e.g. CDs complexed azo-dyes show increased photofading resistance [4].

On the other hand, cyclodextrins or their derivatives show catalytic activity, significantly increasing, for example hydrolysis rate of $m$-tert-butylphenol esters or DNA [5]. Cyclodextrins affect regio- and stereoselectivity of substitution or addition reactions [6-8]. Such behaviour is interpreted as enzyme mimicking action of cyclodextrin [9], in which the macrocyclic component serves as a mediator, taking part in a transfer of the reacting species. Due to these properties CDs are also called molecular reactors [10]. Our preliminary studies revealed, that the yield and the ratio of coupling products of $o$-nitrobenzene-diazonium salt with pyrrole significantly depends on the concentration of $\beta$-cyclodextrin, purposely added to the reaction mixture [11]. Coupling reactions of $o$-ethoxybenzene-diazonium salt with pyrrole, imidazole and 2methylimidazole are affected by $\alpha$-, $\beta$-, or $\gamma$-cyclodextrin so that, not only the yield and the ratio of products is changed, but also formation of additional compounds is promoted [12]. Co-conformation of azole complexes with CDs was assumed to be a key factor, which controls the coupling reaction course [11,12].

The aim of this paper is to demonstrate how CDs influence the overall yield of macrocyclic products formed on coupling of pyrrole, imidazole or substituted imidazoles with bis-diazonium salts. 


\section{Results}

Coupling reactions with pyrrole

Coupling reactions of bis-diazonium salts, derived from bis-1,5-(2aminophenoxy)-3-oxapentane or bis-1,8-(2-aminophenoxy)-3,6-dioxaoctane [13,14], with pyrrole were performed as shown in Scheme 1.

[Insert SCHEME 1 about here]

Addition of $0.25 \mathrm{mmol}$ of $\alpha$-, $\beta$-, or $\gamma$-cyclodextrin per $2 \mathrm{mmol}$ of bis-diazonium salt and 2 mmol of pyrrole changed the total yield and the ratio of products. In case of $\alpha-\mathrm{CD}$, yield of compound $1 p$ increased slightly, whereas yield of compound $2 p$ was almost doubled. When $\beta$-CD was used, the ratio was inverted; product $1 p$ was isolated with yield more than double as compared to plane reaction, whereas amount of product $2 p$ was only a little bit higher. The overall yield of the two macrocyclic compounds formed simultaneously reached $87 \%$. The influence of $\gamma$-cyclodextrin was noted as $\mathbf{1} p$ yield increase and $2 p$ slight decrease. Comparison of the yield of macrocycles obtained from pyrrole in the presence and in the absence of cyclodextrins is presented in Figure 1. 
Interestingly, the 18 -membered compound $\mathbf{1} p$ is accompanied by its isomer $\mathbf{2 p}$, however the respective isomer of $\mathbf{3} \boldsymbol{p}$ of larger cavity was not found.

[Insert FIGURE 1 about here]

Coupling reactions with imidazole and its derivatives

To establish how general the influence of cyclodextrins on macrocyclic products formation is, coupling reactions of bis-diazonium salts with imidazole and its methyl or phenyl derivatives were carried out. The syntheses were performed as shown in Scheme 2.

[Insert SCHEME 2 about here]

Coupling of bis-diazonium salt [derived from bis-1,5-(2-aminophenoxy)-3-oxapentane] with imidazole, and 2- and 4-methylimidazole was performed in the presence of $\alpha-, \beta$, or $\gamma$-cyclodextrin. The most spectacular results were obtained for $\gamma$-CD in the case of 2and 4-methylimidazole (Figure 2). Yield of product $\mathbf{3 i}$ and $\mathbf{7} \boldsymbol{i}$ was as high as 75 and $89 \%$, respectively.

[Insert FIGURE 2 about here] 
Coupling reactions of bis-diazonium salts derived from bis-1,5-(2aminophenoxy)-3-dioxapentane or bis-1,8-(2-aminophenoxy)-3,6-dioxaoctane with imidazole in the presence of $\alpha$-, $\beta$-, or $\gamma$-cyclodextrin show the influence of the ether chain length on the yield of products. The yield of 18- and 21-membered azocrowns $1 i$ and $\mathbf{2} \boldsymbol{i}$ with regard to the ether chain length is presented in Figure 3. Product $\mathbf{1} i$ formation is inhibited in the presence of $\beta$ - or $\gamma-\mathrm{CD}$, whereas addition of $\alpha$-CD has no distinct influence. In case of reaction leading to compound $2 i$ the influence of $\beta$-CD is not substantial, while presence of $\alpha$ - or $\gamma$-CD decreases product $2 i$ yield drastically; only traces of compound were found when the latter one was added to the reaction mixture.

[Insert FIGURE 3 about here]

More coupling experiments with substituted imidazoles and bis-diazonium salts of different oxyethylene chain length were performed in the presence of $\beta$-CD. Results are summarized in Figure 4.

[Insert FIGURE 4 about here]

The highest yield increase in the presence of $\beta-\mathrm{CD}$ was found for macrocycles $7 \boldsymbol{i}$ and 8i. The yield of 17-membered and 20-membered chromogenic, macrocyclic derivatives of 2-methylimidazole is almost two times higher as compared with plain experiment. The yield increase observed for compounds $2 \boldsymbol{i}-\mathbf{6} \boldsymbol{i}$ with $\beta$-CD is less prominent, whereas formation of compound $\mathbf{1 i}$ is retarded in the presence of $\beta$-CD.

\section{Discussion}


Previously, very similar coupling reactions of $o$-ethoxybenzenediazonium salt with pyrrole, or imidazole, or 2-methylimidazole [12] were carried out in the presence of $\alpha$-, $\beta$ - or $\gamma$-cyclodextrin. For comparison, blank experiments were performed under exactly the same experimental conditions (ratio of substrates, concentration, temperature, $\mathrm{pH}$ and isolation procedure). The yield and ratio of the desired compounds (Scheme 3), intermediates, isomers and products of free radical side reactions, were discussed with regard to the applied concentration of CDs.

[Insert SCHEME 3 about here]

Syntheses of these compounds served as model reactions for the analogous syntheses of azocrown ethers considered in this paper. The previously obtained data [12] led to the conclusion that high concentration of CDs (up to $4 \mathrm{mmol}$ per $1 \mathrm{mmol}$ of azole) generally decreases the total yield of coupling and changes the percentage of free radical reaction products. Reaction of $o$-ethoxybenzenediazonium salt with 2methylimidazole at high cyclodextrin concentrations leads mainly to free radical reaction product.

The observed influence of cyclodextrins on model reactions with $o$ ethoxybenzenediazonium salts suggests that reactions leading to azomacrocycles may also be affected by CDs. As high concentration of CDs were unfavourable, only small amounts of CDs were added to the reaction mixtures. At small concentrations of CDs the difference between the blank and CDs promoted reaction should be emphasized, if all conditions are exactly the same as in model reactions. 
The model coupling reactions leading to products shown in Scheme 3 are intermolecular. In case of coupling leading to the macrocyclic compounds, the reaction proceeds in two stages: the first consists in intermolecular coupling of bis-diazonium salt with azole molecule to form first $-\mathrm{N}=\mathrm{N}-$ bond; and the second, intramolecular coupling that closes the macrocyclic unit. Under the applied conditions the CDs influence mainly the second stage.

It is known that diazonium salts [15] and their coupling products form spontaneously complexes with CDs with the typical formation constants in the range of $10^{3}$ to $10^{4}$ $\mathrm{mol}^{-1} \cdot \mathrm{dm}^{3}[16,17]$. It is also known that the inclusion process takes milliseconds or less [18]; for a recent review see $[19,20]$.

Considering the above literature data and the results of model reactions it seems that CDs favour complexation of azoles over benzene residues. In the syntheses of macrocycles the intermediate product formed at the first coupling stage, could also be complexed by CDs.

As shown previously [12], the differences in the yield of the macrocyclic products led to assumption, that the reaction course is stimulated by relative orientation of azole molecule and/or the intermediate inside CDs cavity. The included molecules are normally oriented in the host in such way, that the hydrophobic part of the guest enters the cavity as deep as possible.

Pyrrole macrocycles 
Under standardized conditions, for 18-membered pyrrole azocrown ether $1 p$ the yield increases in the presence of CDs in the order $\beta, \gamma$ and $\alpha$ as compared with the plain experiment. Surprisingly, for the 17-membered isomer $2 p$ the highest yield increase is caused by $\alpha-\mathrm{CD}$, whereas for other CDs the yield is comparable with plain experiment. Looking at the relative yield and the ratio of positional isomers of pyrrole azocrown ether it could be assumed that orientation of the first stage coupling products in CDs cavities is as shown in Scheme 4. Co-conformation "a" is favoured over "b" because in the latter one the pyrrole $\mathrm{NH}$ group occupies the most lipophilic part of $\mathrm{CD}$ cavity. Hence the yield of compound $\mathbf{2 p}$ is generally lower than $\mathbf{1} p$. Taking into account that the position 2 and 5 of pyrrole is more reactive, formation of compound $1 p$ seems to be more favoured than formation of compound $2 p$. These assumptions, however, do not explain tremendous yield increase of $1 p$, and smaller yield increase of $2 p$ in the reactions carried out in the presence of $\beta$-cyclodextrin. It may be supposed that $\mathrm{CD}$ somehow favours intramolecular coupling of intermediate "a".

[Insert SCHEME 4 about here]

For the synthesis of 21-membered pyrrole azocrown $\mathbf{3 p}$ addition of CDs causes yield decrease. It is worth noting that in this case the isomeric 20 -membered crown ether, analogous to $2 p$, is not formed in plain experiment as well as in the presence of CDs.

Imidazole macrocycles 
For 18-membered imidazole derivative $1 i$ the influence of all CDs on yield is not substantial. The influence of CDs on the synthesis of 4-methylimidazole derivative $\mathbf{3 i}$ is better pronounced: $\alpha$-CD reduces the yield, whereas $\gamma-\mathrm{CD}$ enhances macrocycle formation more than double. In case of coupling of 2-methylimidazole, $\alpha$ - and $\beta$-CD demonstrate small desired influence while $\gamma$-CD increases the yield of $7 \boldsymbol{i}$ from $25 \%$ to $89 \%$ as compared with plain synthesis.

Coupling leading to imidazole derivative $\mathbf{1 i}$ is specially sensitive to the presence of $\beta$ $\mathrm{CD}$; the yield is reduced probably because deeply embedded the imidazole moiety is sterically hindered by the host, see scheme 5, "c". In case of 2- or 4-methylimidazole co-conformation "d" and "e" for intermediate CDs complexes are the most probable (Scheme 5). Analysing the experimental data (Figure 2) a steric hindrance was observed only for $\alpha$-cyclodextrin. More, CDs stimulate macrocyclization with the highest effect observed for $\gamma$-CD. It may be interpreted with respect to the CDs cavity size. Probably, the azole- $\mathrm{N}=\mathrm{N}-$ benzene fragment includes into $\gamma-\mathrm{CD}$ cavity enhancing the intramolecular coupling, c.f. $c$ is $\rightleftharpoons$ trans isomerization of azobenzene derivative of $\gamma$ CD [21].

[Insert SCHEME 5 about here]

In case of 4-phenylimidazole coupling $\beta$-CD also influences the yield of compounds $\mathbf{5 i}$

and $6 i$, although the effect is less pronounced; side reactions involving benzene residue or partial expulsion of imidazole residue from CD cavity could be the reason. 
Considering the influence of oxyethylene chain length it could be stated that $\beta$-CD promotes to a greater extent formation of macrocycles; contrary to this $\alpha$-CD and $\gamma$-CD strongly decrease yield of compound $2 i$.

Interestingly, the free radical reactions, which are significant in syntheses leading to open-chained products [11,12], play negligible role in case of syntheses of macrocycles. None free radical reaction product was identified. It suggests that coupling of the diazonium salt with azoles proceeds faster than homolysis.

\section{Conclusions}

As suggested in the literature, under the applied conditions CDs form complexes with organic components of the reaction mixture. The embedded parts of molecules are shielded from the bulk. It may ultimately protect them against side reactions or improve intramolecular reaction. Cyclodextrins have an influence on the formation of macrocyclic compounds comprising pyrrole, imidazole and substituted imidazole. Experiments on coupling bis-diazonium salt(s) with imidazoles in the presence of CDs revealed important influence of lipophilic methyl or phenyl residues on the yield of macrocycles .

Co-conformation of substrates or reaction intermediates hosted in the cyclodextrin cavity is a key factor determining the reaction course. Intramolecular coupling of the intermediate is probably favoured by CDs, and as a result the by-products formation is decreased. Although, cyclodextrins are reported to facilitate homolytic decomposition of diazonium salts and stabilize radical species [15], here we have not observed substantial yield of free radical reaction products. 


\section{Experimental}

All materials and solvents were of analytical reagent grade. $\alpha$-CD (TCI), $\beta$-CD (Fluka) and $\gamma$-CD (TCI) were used as purchased. Isolation of macrocyclic products was performed on silica gel filled chromatographic column or on preparative chromatographic plates (Silica gel $60 \mathrm{~F}_{254}$, Merck). The yield was determined gravimetrically.

Compounds $1 p-3 p$ and $1 i$, including X-ray structure of compound $2 p$ [23], and compounds $\mathbf{2 i}-\mathbf{8 i}$, including X-ray structure of $4 \boldsymbol{i}$ [24] were fully characterized previously and served as reference materials in this study.

\subsection{Syntheses}

Two solutions were prepared:

Solution A. To a suspension of bis-1,5-(2-aminophenoxy)-3-oxapentane or bis-1,8-(2aminophenoxy)-3,6-dioxaoctane [13,14] $(2 \mathrm{mmol})$ in $40 \mathrm{~cm}^{3}$ water $1 \mathrm{~cm}^{3}$ conc. 
hydrochloric acid was added. The clear solution was diazotized with sodium nitrite $(0.28 \mathrm{~g}, 4 \mathrm{mmol})$ dissolved in $2 \mathrm{~cm}^{3}$ cold water.

Solution B. Pyrrole, or imidazole, or 2-methyl-, or 4-methyl- or 4-phenylimidazole (2 mmol) and sodium hydroxide $(0.2 \mathrm{~g}, 5 \mathrm{mmol})$ were dissolved in $40 \mathrm{~cm}^{3}$ water. To solutions containing pyrrole or 4-phenylimidazole $2 \mathrm{~cm}^{3}$ of ethanol was added. In the case of syntheses with cyclodextrins, $0.25 \mathrm{mmol}$ of $\mathrm{CD}$ was added to each solution $\mathrm{B}$.

Ice-cold solutions A and B were added dropwise with the same rate during 45 min to a vigorously stirred cold $\left(10^{\circ} \mathrm{C}\right)$ water $\left(600 \mathrm{~cm}^{3}\right)$ alkalized with $\mathrm{NaOH}$ to $\mathrm{pH} \sim 10$. Then stirring was continued overnight. During the first three hours the temperature was maintained at $10^{\circ} \mathrm{C}$, and then at $20^{\circ} \mathrm{C}$. Finally, the reaction mixture was cooled to $5^{\circ} \mathrm{C}$ and adjusted to $\mathrm{pH} \sim 6$ with acetic acid. The precipitate was collected and the filtrate was extracted with chloroform - toluene - acetic acid (30:1:1) mixture until the aqueous phase decolorizes. Then the extracts were evaporated under reduced pressure. The macrocyclic compounds were isolated and characterized as described in [23,24].

\section{Acknowledgements}

Financial support of this work from Gdansk University of Technology, DS 014668/003, is kindly acknowledged. The authors thank Joanna Tłuszczyk for remarkable experimental help.

\section{References}

(10) Comprehensive Supramolecular Chemistry, Lehn J.-M.; Atwood J.L.; Davies J.E.D.; McNicol D.D.; Vögtle F. (eds.); Cyclodextrins, Vol. 3, J. Szejtli and T. Osa (volume eds.), Pergamon, New York (1996). 
(2) Ueno, A.; Kuwabara, T.; Nakamura, A.; Toda, F. Nature 1992, 356, 136.

(3) Kuwabara T.; Takamura M.; Matsushita A.; Ikeda H.; Nakamura A.; Ueno A.; Toda F. J. Org. Chem. 1998, 63, 8729.

(4) Arunkumar, E.; Forbes, C.C.; Smith B.D. Eur. J. Org. Chem., 2005, 19, 4051.

(5) c.f. Takahashi, K. Chem. Rev. 1998, 98, 2013.

(6) Breslow, R.; Campbell, P. J. Am. Chem. Soc. 1969, 91, 3085.

(7) Schneider, H-J.; Sangwan, N.K. Angew. Chem. Int. Ed. Eng. 1987, 26, 896.

(8) Manickam, M.C.D.; Annalakshmi, S.; Titchumani, K.; Srinivasana, C. Org. Biomol. Chem. 2005, 3, 1008.

(9) Komiyama, M; Shigekawa, H. Cyclodextrins as EnzymeModels, see reference (1), pp. 401-422.

(10) Barr, L.; Dumanski, P.G.; Easton, C.J.; Harper, J.S.; Lee, K.; Lincoln, S.F.; Meyer, A.G.; Simpson, J.S. J. Incl. Phenom. Macrocycl. Chem. 2004, 50, 19.

(11) Jamrógiewicz , M.; Biernat, J.F. Polish J. Chem. 2006, 80, 753.

(12) Jamrógiewicz, M.; Sadowska, K.; Biernat, J.F. J. Incl. Phenom. Macrocycl. Chem. 2006, 56, 355.

(13) Skwierawska, A.; Inerowicz, H.D.; Biernat, J.F. Tetrahedron Lett. 1998, 39, 3057.

(14) Wagner-Wysiecka, E.; Skwierawska, A.; Kravtsov, V.Ch.; Biernat, J.F. J. Supramol. Chem. 2001, 1, 77.

(15) Gonzalez-Romero, E.; Malvido-Hermelo, B.; Bravo-Diaz, C. Langmuir 2002, 18, 46.

(16) Hirai, H.; Toshima, N.; Uenoyama, S. Bull. Chem. Soc. Jpn. 1985, 58, 1156.

(17) Mourtzis, N.; Cordoyiannis, G.; Nounesis, G. Supramol. Chem. 2003, 15, 639.

(18) Yoshida N.; Hayashi, K. J. Chem. Soc. Perkin Trans. 2 1994, 1285.

(19) Luboch E.; Poleska-Muchlado Z.; Jamrógiewicz M.; J.F. Biernat: Cyclodextrin combinations with azocompounds in K.Gloe (ed.), Macrocyclic Chemistry - Current Trends and FuturePerspectives,

Springer, Dordrecht (2005), pp. 203-218.

(20) Luboch, E.; Bilewicz, R.; Kowalczyk, M.; Wagner-Wysiecka, E.; Biernat, J.F. Azo Macrocyclic Compounds, Chapter 3; in Advances in Supramolecular Chemistry, Gokel, G.W., (ed).; Cerberus Press, 2003; Vol. 9; pp. 71-162.

(21) Hamada, F.; Fukushima M.; Osa T.; Ikeda H.; Toda F.; Ueno A. Macromol. Chem. Rapid Commun. 1993, 14, 287. 
(22) Sanders, J.K.M. Pure Appl. Chem. 2000, 72, 2265.

(23) Wagner-Wysiecka, E.; Luboch, E.; Kowalczyk, M.; Biernat, J. F. Tetrahedron 2003, 59, 4415.

(24) Wagner-Wysiecka E.; Jamrógiewicz M.; Fonari M.S.; Biernat J.F. Tetrahedron 2007, 63, 4414

(2007). 


\section{SCHEMES}

SCHEME 1. Syntheses of azocrown ethers with pyrrole units in the presence of cyclodextrins

SCHEME 2. Syntheses of azocrown ethers with imidazole or imidazole derivative units

SCHEME 3. Products of double coupling of $o$-ethoxybenzenediazonium salt with azoles

SCHEME 4. Considered co-conformations of pyrrole molecules embedded in CDs

SCHEME 5. Considered co-conformations of imidazole molecules embedded in CDs

\section{FIGURES}

FIGURE 1. Yield of macrocyclic products obtained from pyrrole and bis-diazonium salts in the presence and in the absence of cyclodextrins.

FIGURE 2. Yield of macrocyclic products, obtained from bis-diazonium salt and imidazole or its derivatives in the presence and in the absence of cyclodextrins

FIGURE 3. Yield of 18- and 21-membered macrocycles with imidazole units in the presence and in the absence of cyclodextrins

FIGURE 4. Yield of macrocyclic products obtained from bis-diazonium salts and imidazole or its derivatives in the presence and in the absence of $\beta$-cyclodextrin 


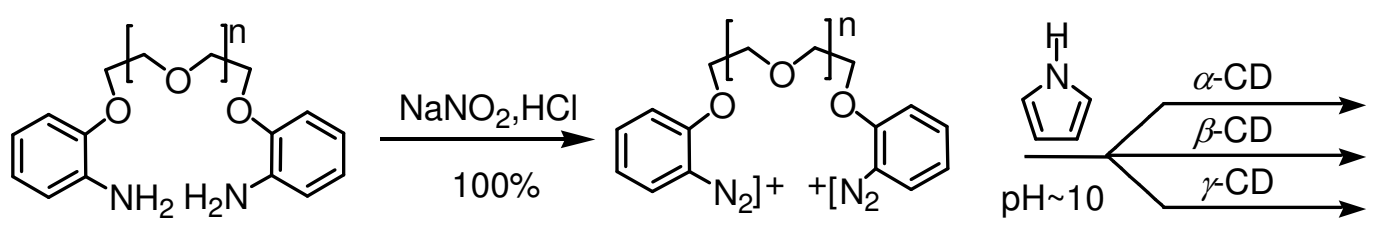<smiles>CCOCCOc1ccccc1N=Nc1ccc(N=Nc2ccccc2OCCOCC)[nH]1</smiles><smiles>OCCOCCOc1ccccc1N=Nc1[nH]ccc1N=Nc1ccccc1</smiles>

$1 p, \mathrm{n}=1$

$3 p, n=2$

$2 p$

\section{SCHEME 1}




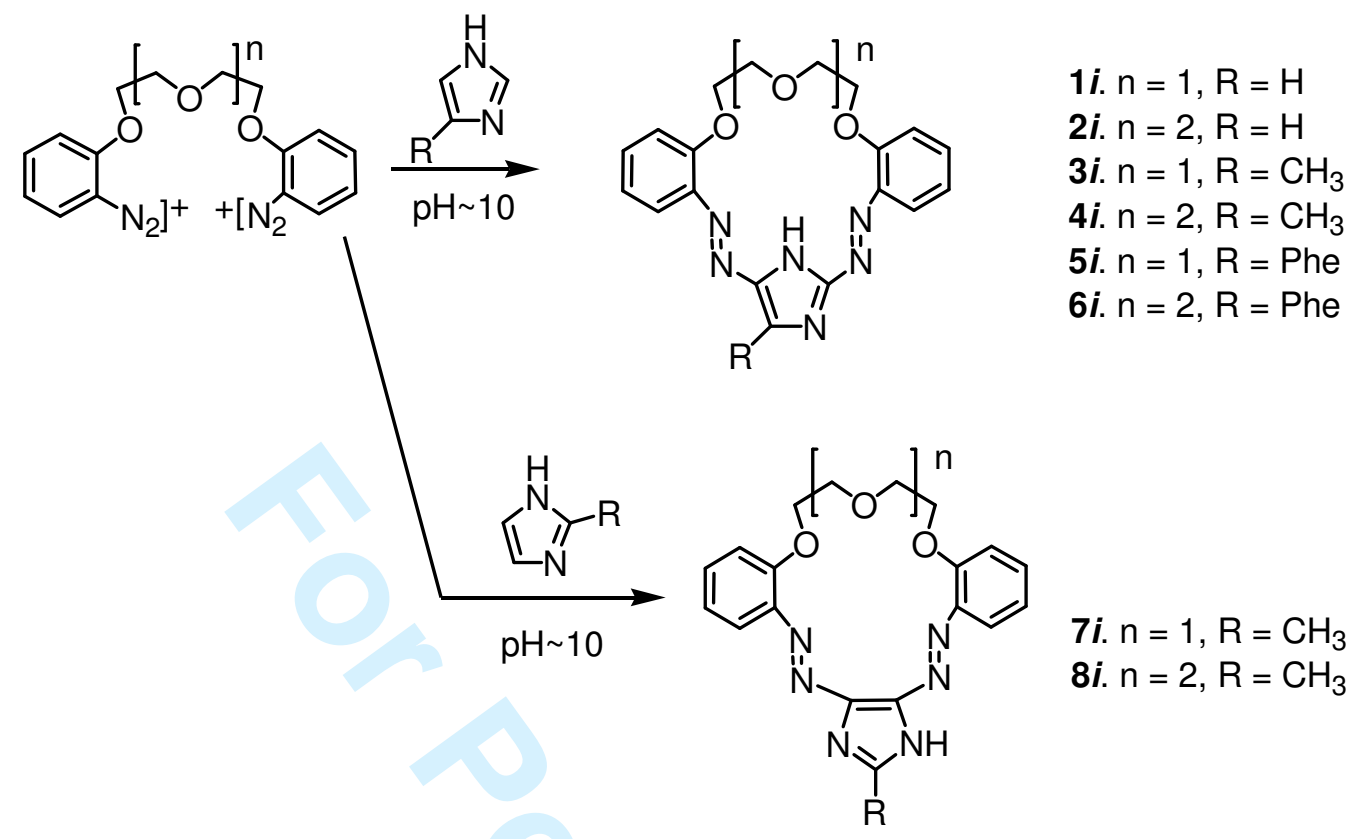

SCHEME 2 

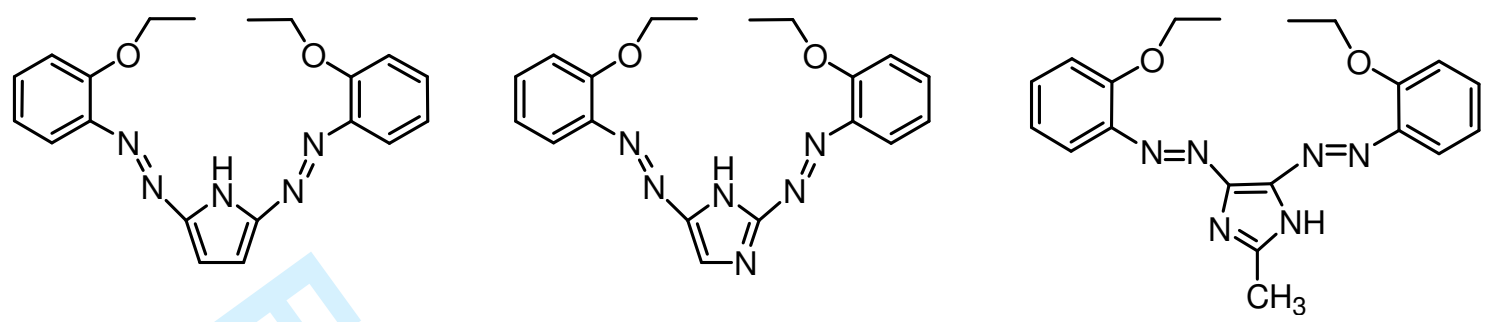

\section{SCHEME 3}




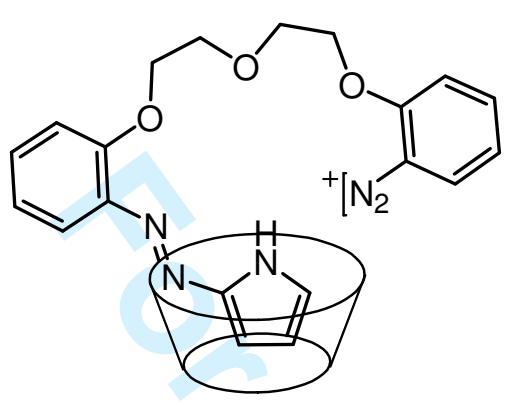

a

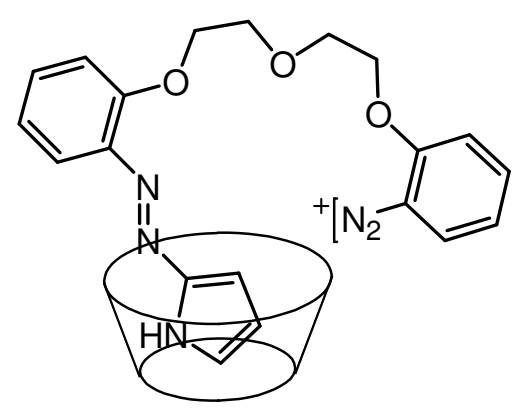

b

\section{SCHEME 4}




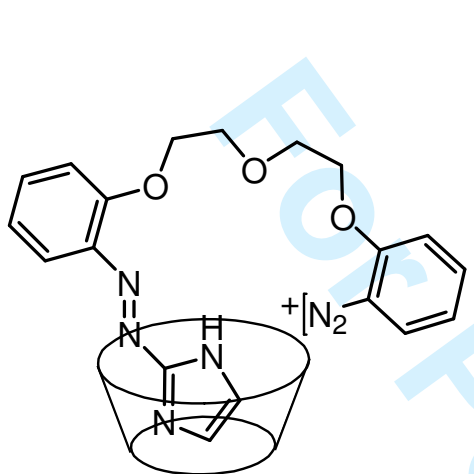

C

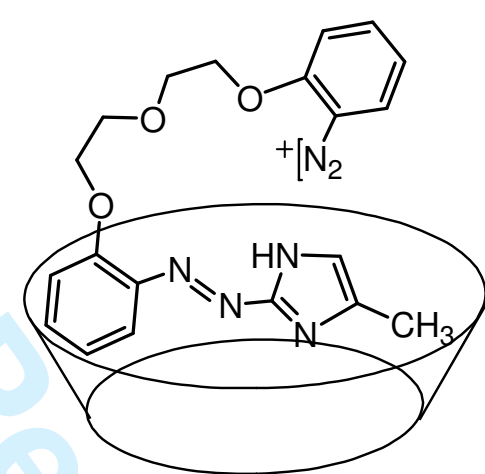

d

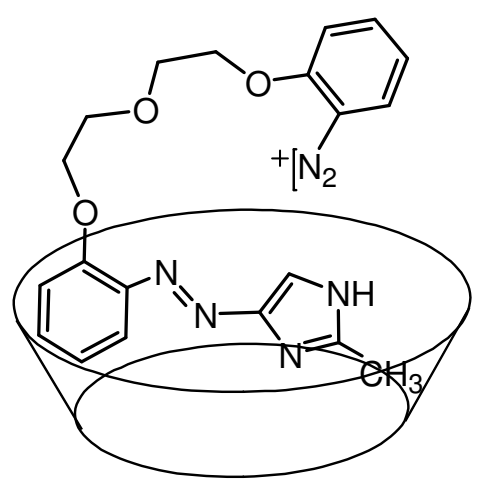

e

\section{SCHEME 5}




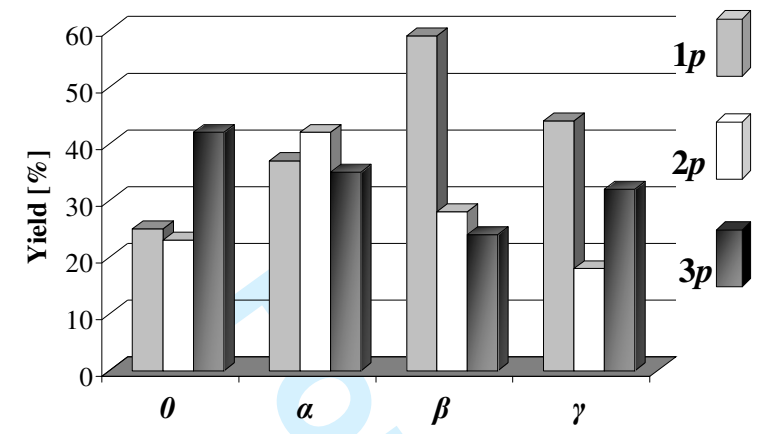

FIGURE 1

URL: http:/mc.manuscriptcentral.com/tandf/gsch Email: suprachem@mail.cm.utexas.edu 


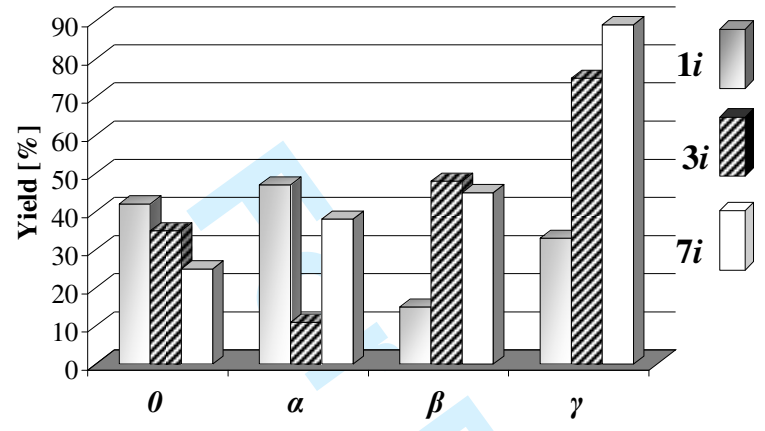

\section{FIGURE 2}

URL: http:/mc.manuscriptcentral.com/tandf/gsch Email: suprachem@mail.cm.utexas.edu 


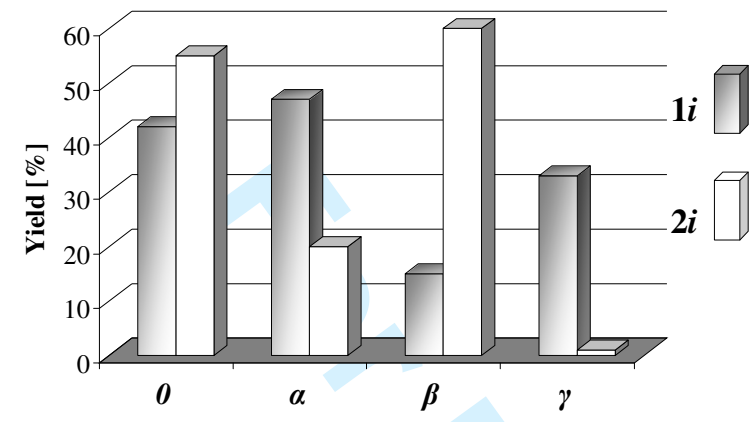

\section{FIGURE 3}

URL: http:/mc.manuscriptcentral.com/tandf/gsch Email: suprachem@mail.cm.utexas.edu 


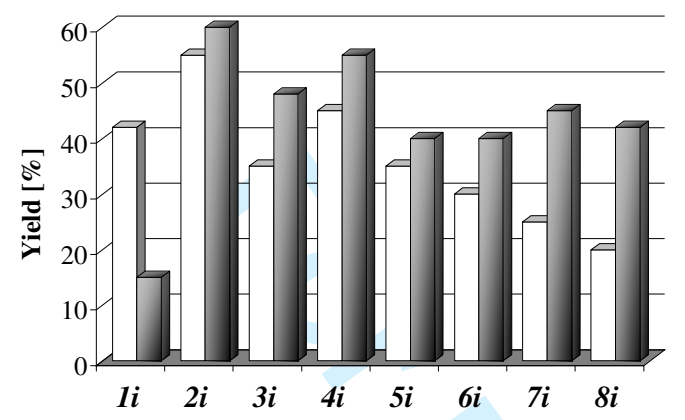

$$
\text { without CD } \llbracket \quad \text { with } \beta \text {-CD }
$$

\section{FIGURE 4}

URL: http:/mc.manuscriptcentral.com/tandf/gsch Email: suprachem@mail.cm.utexas.edu 


1
2
3
4
5
6
7
8
9
10
11
12
13
14
15
16
17
18
19
20
21
22
23
24
25
26
27
28
29
30
31
32
33
34
35
36
37
38
39
40
41
42
43
40
45
49
50
51
52
53
55
50

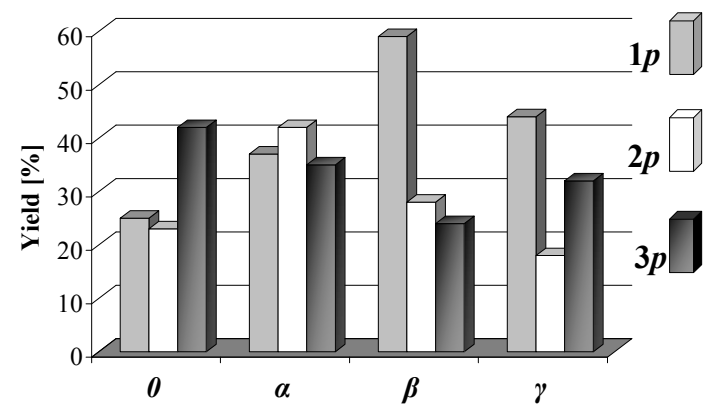

figure 1

15

16

17

18

19

20

21

23

24

27

28

30

31

32

33

34

35

36

37

39

40

41

42

43

44

46

47

48

49

50

52

53

54

55

56

57

58

59

URL: http:/mc.manuscriptcentral.com/tandf/gsch Email: suprachem@mail.cm.utexas.edu 


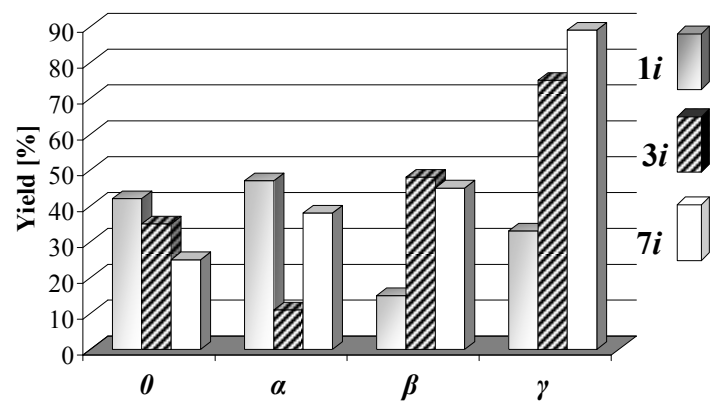

figure 2

14

15

16

17

18

19

20

21

22

23

24

25

26

27

28

29

30

31

32

33

34

35

36

37

38

39

40

41

42

43

44

45

46

47

48

49

50

51

52

53

54

55

56

57

58

59

60

URL: http:/mc.manuscriptcentral.com/tandf/gsch Email: suprachem@mail.cm.utexas.edu 


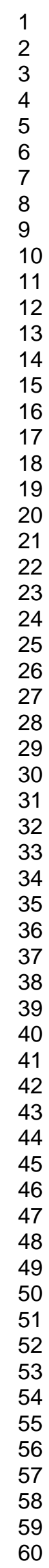

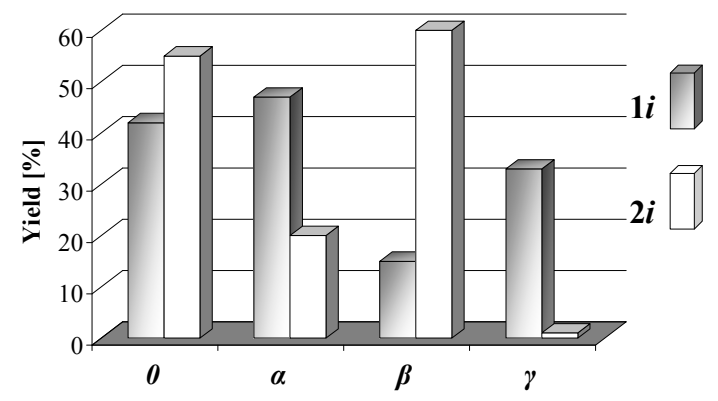

figure 3 \\ Page 27 of 28}

2

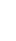
10 

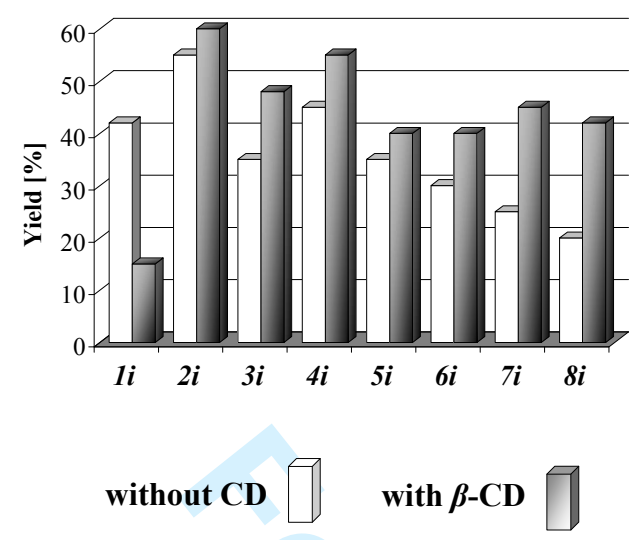

\section{figure 4}

